\title{
A Comparative Study on Biological Activity of Schiff bases Derived from 2-(2-amino)-3-(1H-indol-3-yl)propanoic acid
}

\section{SANTHI RADHAKRISHNAN ${ }^{*}$, RAJESWARI BALAKRISHNAN ${ }^{2}$ and AHALYA SELVARAJ ${ }^{3}$}

1,2,3PG and Research Department of Chemistry, Seethalakshmi Ramaswami College, Affiliated to Bharathidasan University, Tiruchirappalli-620 002, Tamil Nadu, India. ${ }^{2}$ K.Ramakrishnan College of Engineering, Kariyamanikam Road, Samayapuram, Tiruchirappalli-621 112, Tamil Nadu, India.

*Corresponding author E-mail: santhichemsrc@gmail.com

http://dx.doi.org/10.13005/ojc/360426

(Received: May 10, 2020; Accepted: July 15, 2020)

\begin{abstract}
Indole group containing four different Schiff bases such as 2-((2-hydroxybenzylidene)amino)-3(1H-indol-3-yl)propanoic acid, 2,2'-((1Z,1'E)-(1,4-phenylenebis(methanylylidene))bis(azanylylidene)) bis(3-(3a,7a-dihydro-1H-indol-3-yl)propanoic acid), (E)-2-((2-chlorobenzylidene)amino)-3-(3a,7adihydro-1H-indol-3-yl)propanoic acid and (E)-2-((4-chlorobenzylidene)amino)-3-(3a,7a-dihydro$1 \mathrm{H}$-indol-3-yl)propanoic acid were synthesized from Tryptophan and respective aldehydes namely Salicylaldehyde, Terephthalaldehyde, 2-Chlorobenzaldehyde and 4-Chlorobenzaldehyde. A polymeric composite was prepared by doping the Schiff base derived from salicylaldehyde on polyaniline chloride. These compounds were characterized by Fourier-transform infrared (FTIR), UV-Visible, ${ }^{1} \mathrm{H}-\mathrm{NMR}$ spectroscopic techniques. The Schiff Bases and polymer have been examined for their antimicrobial activity. Antibacterial and antifungal activities of all the compounds were studied by Kirby Bauer Agar well diffusion method. In addition Anti-Tubercular study was also performed. It has been found that all the five compounds have remarkable antimicrobial activity.
\end{abstract}

Keywords: Tryptophan, Chlorobenzaldehyde, Schiff Base, Polymer and antimicrobial.

\section{INTRODUCTION}

The preparation of imines was first reported in the $19^{\text {th }}$ century by Hugo Schiff (1864). In the recent past years various methods including solvent free synthesis and microwave irradiation have been reported for the synthesis of Schiff bases ${ }^{1}$. Schiff bases have photochromic and thermochromic properties that made it to be used in modern technologies such as optical computers, measuring the intensity of radiation, imaging system and in molecular memory storage $e^{2,3}$. These imines are found to have various applications in food industry, dye industry, agrochemical industry and catalysis. In Chemistry, Schiff bases are used in quantitative analysis as potentiometric sensors, solvent extraction reagents and solid phase extraction sorbent ${ }^{4}$. In addition to these applications right from $19^{\text {th }}$ century in the field of antimicrobial drugs, the imines are found to play a vital role. Schiff base compounds

This is an Open Access article licensed under a Creative Commons license: Attribution 4.0 International (CC- BY). Published by Oriental Scientific Publishing Company @ 2018

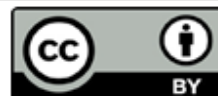


are key part of coordination chemistry as they lead to the formation of stable complexes ${ }^{5}$. Schiff bases are said to have antibacterial ${ }^{6}$, antiviral ${ }^{7}$, antifungal ${ }^{8}$, anticancer ${ }^{9}$, antitubercular ${ }^{10}$, antimalarial ${ }^{11}$, analgesic ${ }^{12,13}$, anti-inflammatory ${ }^{14}$, anticonvulsant ${ }^{15}$ and antioxidant ${ }^{16}$ properties. Tryptophan is a nonpolar aromatic amino acid which is less explored in the field of antimicrobial activity. Tuberculosis is an airborne respiratory disease and in India there are more than 1 million cases is being reported per year. In the present investigation, the aim is to synthesise some new Schiff bases from tryptophan and to study antibacterial activity against certain pathogens such as Bacillus subtilis, Enterococcus, Proteus vulgaris, Staphylococcus aureus, Klebsiella pneumonia, Pseudomonas aeruginosa, Salmonella typhi, Escherichia coli, antifungal activity against Candida albicans, Trichoderma, Aspergillus niger and antitubercular actitvity using Mycobacterium tuberclosis. An attempt is also made to understand antimicrobial activities of a polymer by doping 2-((2-hydroxybenzylidene)amino)-3-(1H-indol-3yl)propanoic acid on polyaniline chloride and to compare with that of Schiff bases.

\section{MATERIALS AND METHODS}

\section{Materials}

Commercially available AR-grade chemicals and solvents were purchased and used as such. A Buchi melting point apparatus was used to determine the melting points of the Schiff base compounds. UV-Visible Spectrophotometer (Perkin Elmer Lambda 35) was used to record UV-Visible spectrum. FTIR spectral measurements were carried out using Perkin Elmer FTIR spectrophotometer. H1-NMR spectra were recorded on Bruker 400 NMR spectrometer using TMS as standard.

\section{METHODS}

\section{Synthesis of Schiff bases}

The azomethine compounds were synthesized by condensing Tryptophan and corresponding carbonyl compounds in the ratio 1:1 except terephthalaldehyde (2:1). Tryptophan and aldehydes were ground well in presence of small amount of acetic acid. The resulting mixture was refluxed for 4-6 hours. The product formed was filtered, washed with ethanol and dried using anhydrous $\mathrm{CaCl}_{2}$ in a vacuum desiccator. The samples were recrystalised with ethanol.

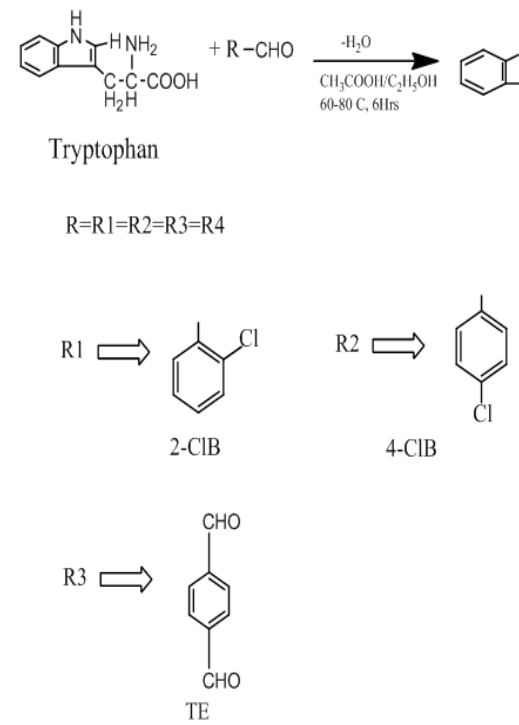

Fig. 1. Scheme of Synthesis of Schiff Bases

\section{Preparation of Poly aniline chloride}

Aniline $(0.1 \mathrm{M})$ was dissolved in aqueous solution of hydrochloric acid $(1 \mathrm{M})$. The mixture was stirred using magnetic stirrer and an aqueous potassium persulphate solution $(0.1 \mathrm{M})$ was added drop wise to the aniline-acid mixture for about two hours with continuous stirring at room temperature. After the addition of potassium persulphate the stirring was continued to ensure complete polymerisation. The PANI formed was green in colour. It was filtered using Whatmann No:1 filter paper and washed with distilled water many times to remove excess acid content and oligomers of aniline followed by ethanol, acetone and diethyl ether. The polymer was dried in an oven at about $373 \mathrm{~K}$ for four hours till constant weight was reached ${ }^{17}$.

The colour changes that appeared during the addition of potassium persulphate is given below;

Straw yellow $\rightarrow$ Yellow $\rightarrow$ Brown $\rightarrow$ Green colour

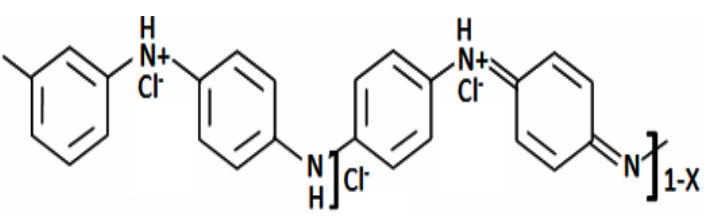

Fig. 2. Structure of PANI chloride

Preparation of Polyaniline chloride-Schiff base Composite

Polyaniline chloride $(0.1 \mathrm{~g})$ and Schiff base 
$(0.1 \mathrm{~g})$ were mixed together in $25 \mathrm{~mL}$ of diethyl ether and sonicated for one hour ${ }^{16}$. The resulting slurry was washed with ether and centrifuged. The resulting green coloured mass was dried in a vacuum desiccator to get a free flowing powder.

\section{Biological activity}

The Schiff bases (2-((2-hydroxybenzylidene) amino)-3-(1H-indol-3-yl)propanoic acid, 2,2'$\left(\left(1 Z, 1^{\prime} E\right)-(1,4-\right.$ phenylenebis (methanylylidene)) bis(azanylylidene))bis(3-(3a,7a-dihydro-1 $\mathrm{H}$-indol3-yl)propanoic acid), (E)-2-((2-chlorobenzylidene) amino)-3-(3a,7a-dihydro-1H-indol-3-yl)propanoic acid and (E)-2-((4-chlorobenzylidene)amino)3-(3a,7a-dihydro-1H-indol-3-yl)propanoic acid) and the polymeric composite were screened for antibacterial, antifungal and antitubercular activity by well method. Bacterial cultures such as Bacillus subtilis, Staphylococcus aureus, Enterococcus, Proteus vulgaris, Salmonella typhi, Klebseilla puminia, Escherichia coli, Pseudomonas aeruginosa were used for understanding antibacterial activity and Candida albicans, A. niger and Trichoderma have been applied to study antifungal activity. Anti tubercular activity was evaluated using Mycobacterium tuberculosis. Nutrient agar medium was used for culture of bacteria. $3.0 \mathrm{~g}$ of beef- extract, $5.0 \mathrm{~g}$ of sodium chloride, $15.0 \mathrm{~g}$ of agar-agar were added into $1000 \mathrm{~mL}$ of distilled water. Then this medium was autoclaved at $15 \mathrm{psi}$ and $394 \mathrm{~K}$ for $15 \mathrm{~min}$, then the medium was allowed to solidify by pouring into the sterile petriplates. A sterile bud was used to swab the bacterial broth culture on each petriplates. Five wells ( 4 wells in periphery and 1 in centre) were made in the medium and subsequently peripheral wells were filled with 25, 50, 75, $100 \mathrm{ppm}$ solutions of synthesized compound respectively and the central well was filled with gentamicin at the same concentration. Other petridishes were sealed with paraffin and incubated at $310-311 \mathrm{~K}$ for bacterial strain and $298 \mathrm{~K}$ (fungi) by following the general procedure. Gentamycin has been employed as a control. After incubation the plates have been examined for the zone of inhibition(ZOI) and compared with that of the standard one.

\section{RESULTS AND DISCUSSION}

The imines and polymeric composite have been synthesized using reported procedure. The yield was good and all compounds were found to be stable. The physical properties of the synthesized compounds are mentioned in Table 1.

\section{IR Spectra}

In the FTIR spectra, the appearance of azomethine $-\mathrm{HC}=\mathrm{N}$ band in the range 1651-1664 $\mathrm{cm}^{-1}$ confirms the formation of Schiff bases (TRSA, TPTE, TP2CIB, TP4CIB). The bending vibrations of the various groups are found in the region 400$960 \mathrm{~cm}^{-1}$. The bending vibrations below $600 \mathrm{~cm}^{-1}$ corresponding to $\mathrm{OH} \& \mathrm{Cl}$ present in the carbonyl moiety. The bands at $1436-1516 \mathrm{~cm}^{-1}$ are due to $\mathrm{C}=\mathrm{C}$ of aromatic ring. The band in the region of 3003-3060 $\mathrm{cm}^{-1}$ may be assigned to aromatic and aliphatic $\mathrm{C}-\mathrm{H}$ groups ${ }^{18}$. The bands at 3388-3427 $\mathrm{cm}^{-1}$ are ascertained to $\mathrm{NH}$ group of the tryptophan moiety (Fig. 3a-3d). FT-IR spectra of PANI composite (Fig. 3e) shows a band in the region $3233 \mathrm{~cm}^{-1}$ which are due to $\mathrm{N}-\mathrm{H}, \mathrm{C}-\mathrm{H}$ and $\mathrm{O}-\mathrm{H}$ stretching vibrations in the polymer. Appearance of bands in the region 600-800 $\mathrm{cm}^{-1}$ are due to $p$-disubstituted aromatic ring in the PANI backbone. A peak at $1501 \mathrm{~cm}^{-1}$ may be due to $-\mathrm{C}=\mathrm{C}$ present in aromatic ring. The stretching frequency at $1588 \mathrm{~cm}^{-1}$ has been assigned to the $\mathrm{C}-\mathrm{C}$ vibrations in benzenoid and quinoid forms. A characteristic band at $1618 \mathrm{~cm}^{-1}$ may be due to $-\mathrm{HC}=\mathrm{N}$ stretching mode of Schiff base doped on polyaniline.

\section{Electronic spectra}

The electronic spectra of Schiff base compounds were recorded using DMSO as solvent between $200-700 \mathrm{~nm}$ at room temperature. Two bands are observed in the region of 296-308nm corresponding to $\pi-\pi^{*}$ transition of phenyl rings in tryptophan molecule. A broad band at $321-360 \mathrm{~nm}$ may be due to $n-\pi^{*}$ transition of azomethine $-\mathrm{HC}=\mathrm{N}$ chromophore. It is well known that Schiff bases exhibit two peaks for $\pi-\pi^{*}$ transition which are very sharp at lower wavelength region, while $n-\pi^{*}$ band occurring between higher wavelength region is a broad band ${ }^{19,20}$ (Fig. 4a-4d). In the electronic spectra of polymeric composite, a band at $320 \mathrm{~nm}$ may be attributed to the presence of $-\mathrm{HC}=\mathrm{N}$ group and a band at about $622 \mathrm{~nm}$ indicate that the composite contain PANI skeleton (Figure 4e).

\section{${ }^{1} \mathrm{H}$ NMR Spectra}

The $1 \mathrm{H}$ NMR spectra of the Schiff bases were recorded in DMSO. The peaks due to azomethine proton appear at $7.5-8.1 \mathrm{ppm}$ for all the prepared imines ${ }^{21}$. The signals at $6.7-7.5 \mathrm{ppm}$ can 
be ascribed to Schiff base aromatic protons. A peak at $10.9 \mathrm{ppm}$ corresponding to the acidic proton of tryptophan moiety is observed for all the compounds. In TPSA a small peak appears at $4.3 \mathrm{ppm}$ due to the presence of phenolic proton of salicylaldehyde (Figure 5a-5d).

The ${ }^{1} \mathrm{H}-\mathrm{NMR}$ spectra (Fig.5e) of the composite shows signal at $\delta 10.2-10.8 \mathrm{ppm}$ due to the $-\mathrm{OH}$ proton of carboxyl group present in dopant. The signal at $8.2 \mathrm{ppm}$ are due to imine protons in Schiff base. The signals at $87.0-7.6 \mathrm{ppm}$ are due to PANI aromatic $-\mathrm{CH}$ and $-\mathrm{NH}$ protons. The peaks at $86.8-6.9$ ppm may be attributed to quinoid $\mathrm{CH}$ protons.

\section{Thermo Gravimetric Analysis}

TGA thermogram recorded for PANI chloride-Schiff base composite is presented in Fig. 6. It shows that the polymeric composite is stable upto $600^{\circ} \mathrm{C}$ as the compound exhibits a linear decline upto $600^{\circ} \mathrm{C}$, after which there is no weight loss.

Table 1: Physical data of the compounds

\begin{tabular}{|c|c|c|c|c|c|c|}
\hline S. No & Entry & IUPAC Name & Molecular Formula & Molecular Weight & Colour & Melting point \\
\hline 1 & TRSA & $\begin{array}{l}\text { 2-((2-hydroxybenzylidene)amino)-3- } \\
\text { (1H-indol-3-yl)propanoic acid }\end{array}$ & $\mathrm{C}_{18} \mathrm{H}_{17} \mathrm{~N}_{2} \mathrm{O}_{3}$ & 309.34 & Yellow & $196^{\circ} \mathrm{C}$ \\
\hline 2 & TPTE & $\begin{array}{l}2,2^{\prime}-\left(\left(1 Z, 1^{\prime} E\right)-(1,4-p h e n y l e n e b i s\right. \\
\text { (methanylylidene))bis(azanylylidene)) } \\
\text { bis(3-(3a,7a-dihydro-1H-indol-3-yl) } \\
\text { propanoic acid) }\end{array}$ & $\mathrm{C}_{19} \mathrm{H}_{17} \mathrm{~N}_{2} \mathrm{O}_{3}$ & 321.35 & White & $130^{\circ} \mathrm{C}$ \\
\hline 3 & TP2CIB & $\begin{array}{l}\text { (E)-2-((2-chlorobenzylidene) } \\
\text { amino)-3-(3a,7a-dihydro-1H- } \\
\text { indol-3-yl)propanoic acid }\end{array}$ & $\mathrm{C}_{18} \mathrm{H}_{16} \mathrm{~N}_{2} \mathrm{O}_{2} \mathrm{Cl}$ & 327.78 & Sandal & $173^{\circ} \mathrm{C}$ \\
\hline 4 & TP4CIB & $\begin{array}{l}\text { (E)-2-((4-chlorobenzylidene) } \\
\text { amino)-3-(3a,7a-dihydro-1H- } \\
\text { indol-3-yl)propanoic acid }\end{array}$ & $\mathrm{C}_{18} \mathrm{H}_{16} \mathrm{~N}_{2} \mathrm{O}_{2} \mathrm{Cl}$ & $327.78 s$ & Pale Yellow & $230^{\circ} \mathrm{C}$ \\
\hline
\end{tabular}

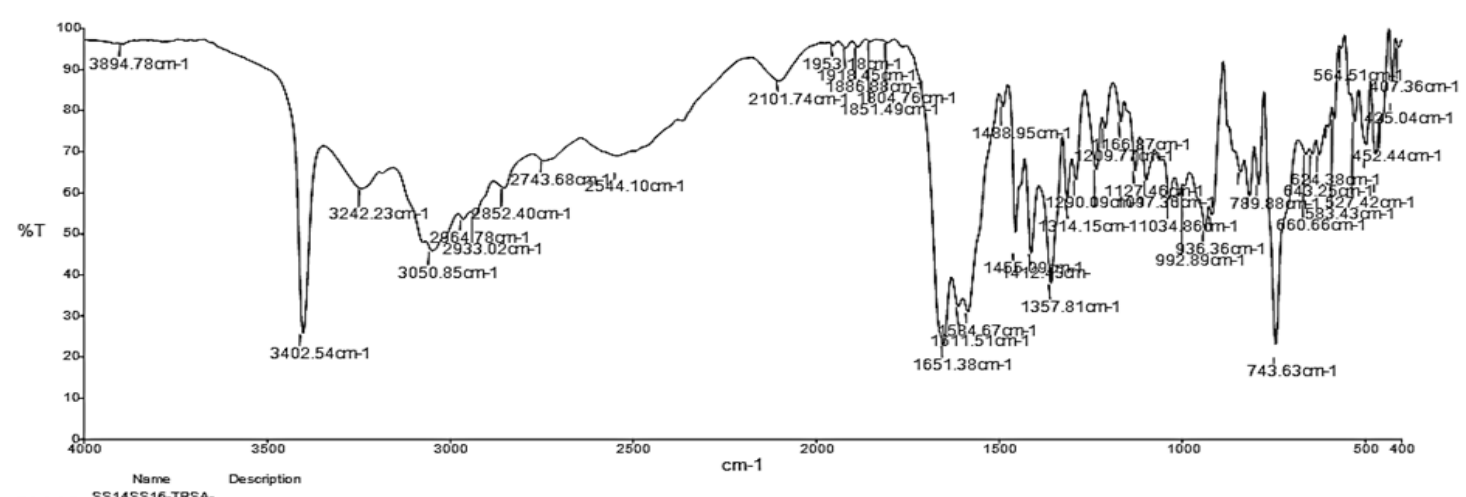

Fig. 3a. IR spectrum of TPSA

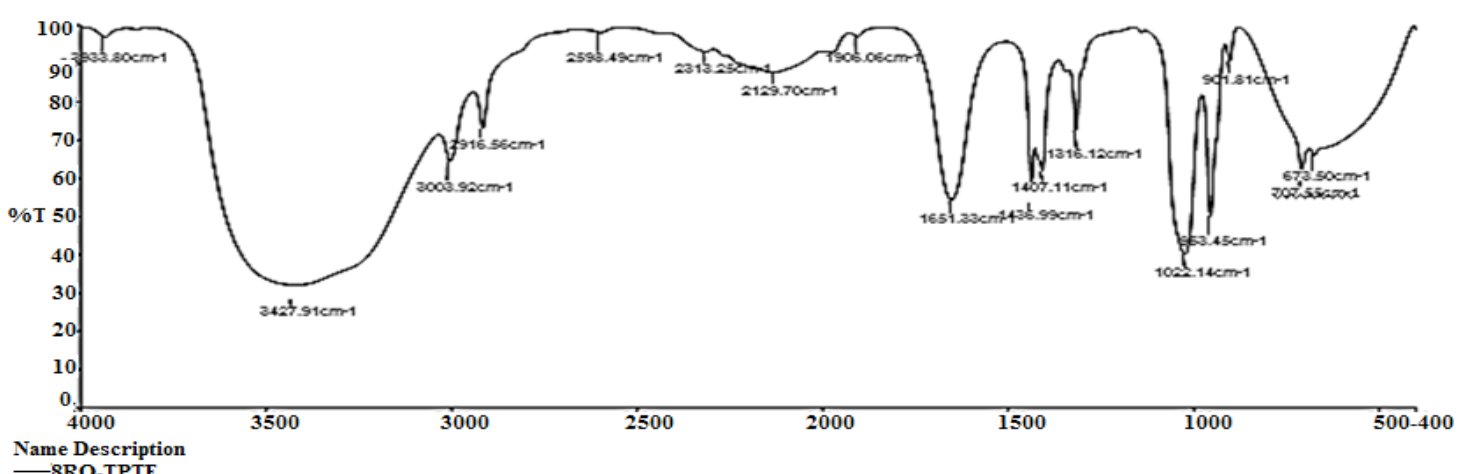

Fig. 3b. IR spectrum of TPTE 


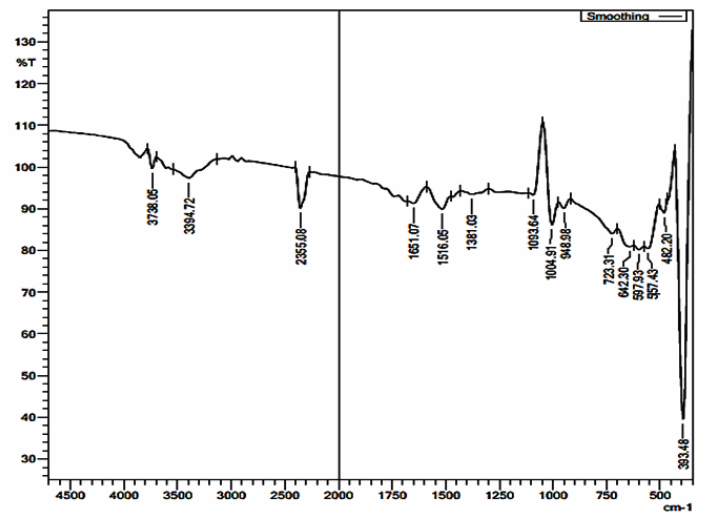

Fig. 3c. IR spectrum of TP2CIB

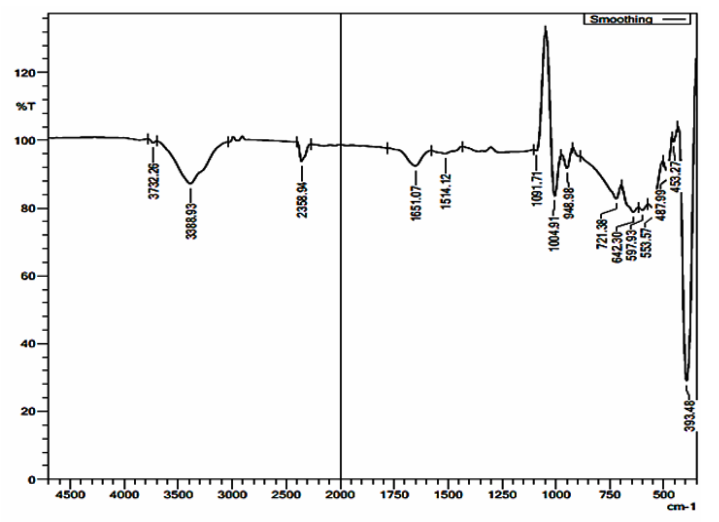

Fig. 3d. IR spectrum of TP4CIB

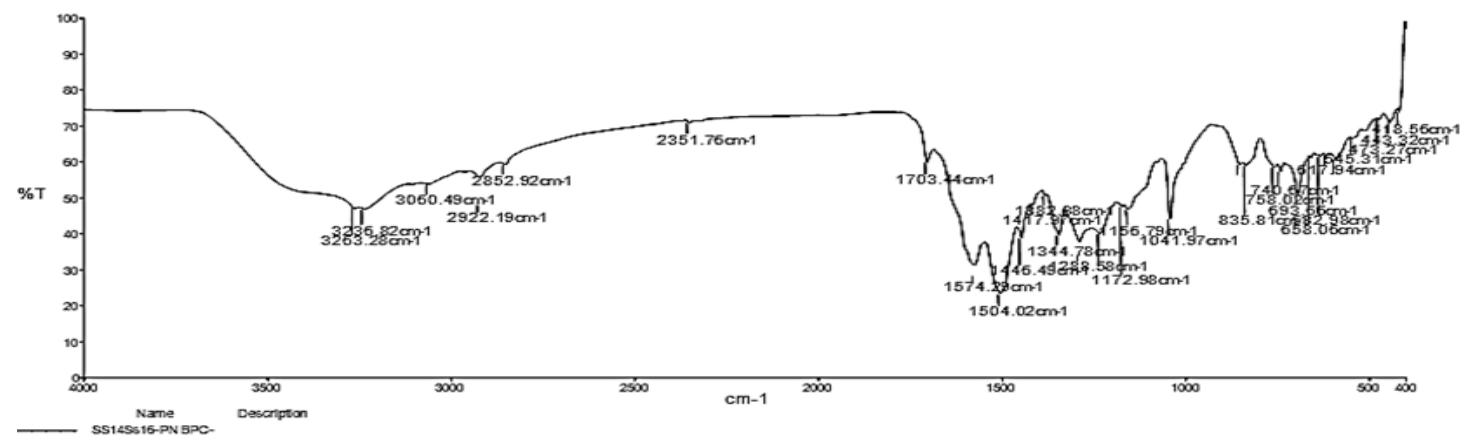

Fig. 3e. IR spectrum of Polymeric composite

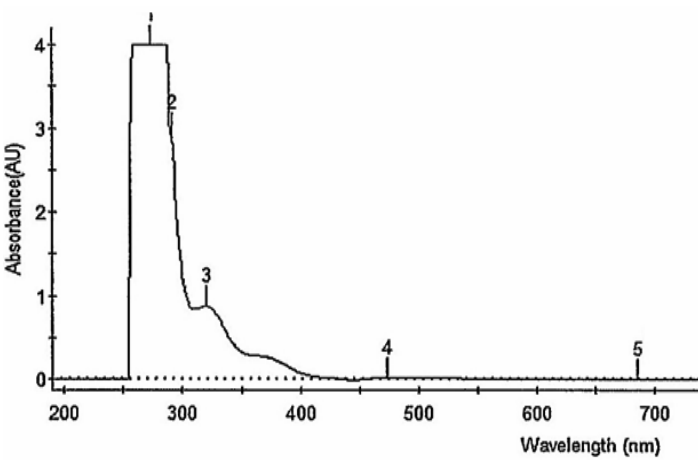

Fig. 4a. UV-Visible spectrum of TPSA

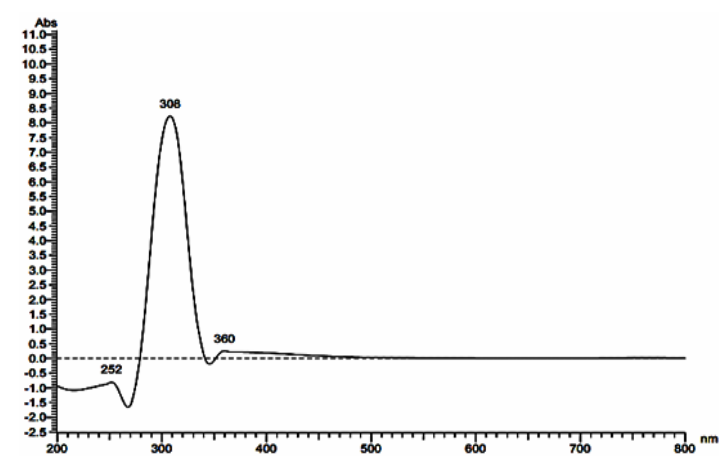

Fig. 4b. UV-Visible spectrum of TPTE

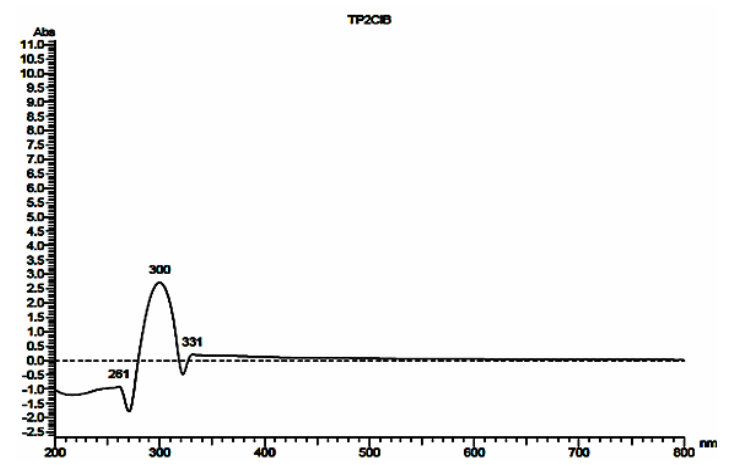

Fig. 4c. UV-Visible spectrum of TP2CIB

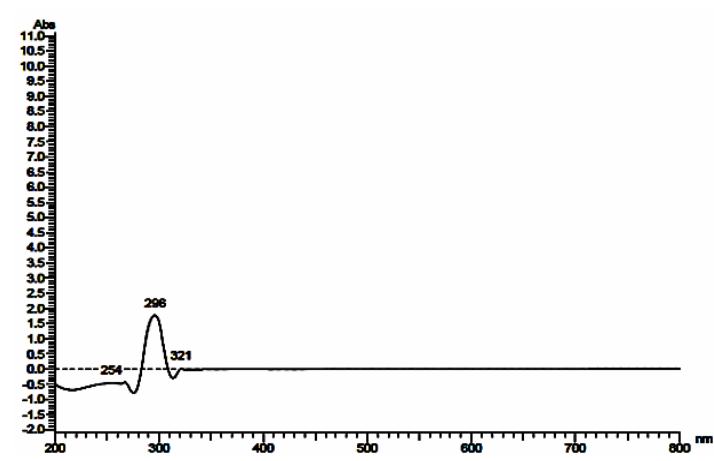

Fig. 4d. UV-Visible spectrum of TP4CIB 


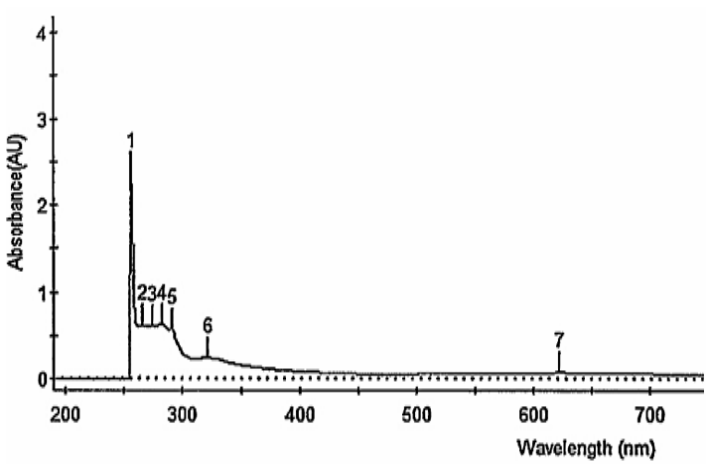

Fig. 4e. UV-Visible spectrum of Polymeric composite

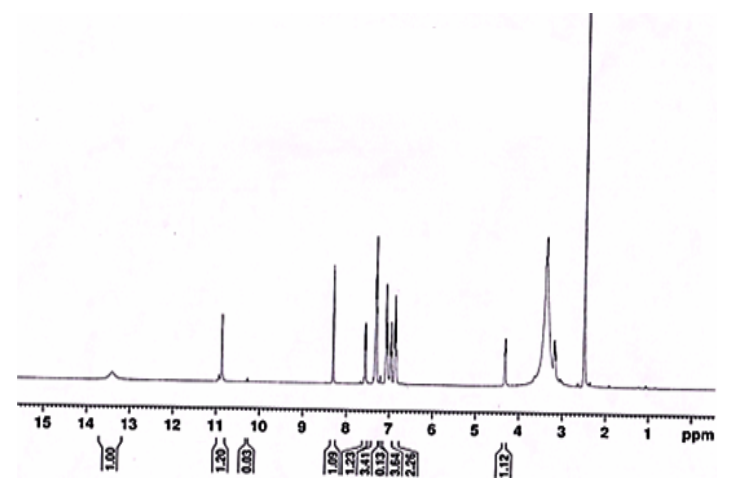

Fig. 5a. ${ }^{1} \mathrm{H}-\mathrm{NMR}$ Spectrum of TPSA

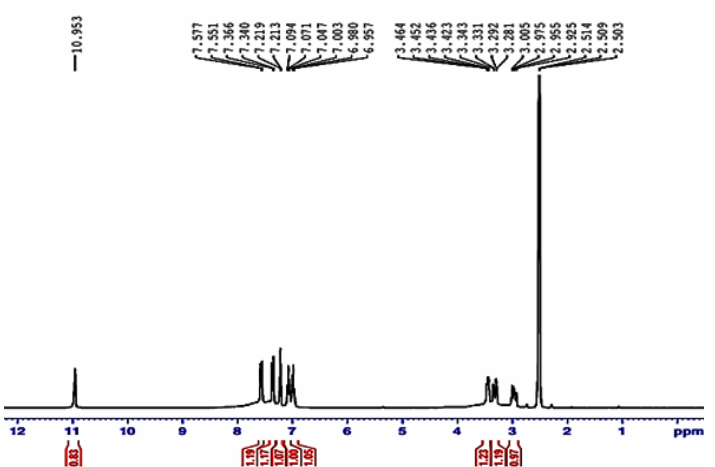

Fig. 5b. ${ }^{1} \mathrm{H}-\mathrm{NMR}$ Spectrum of TPTE

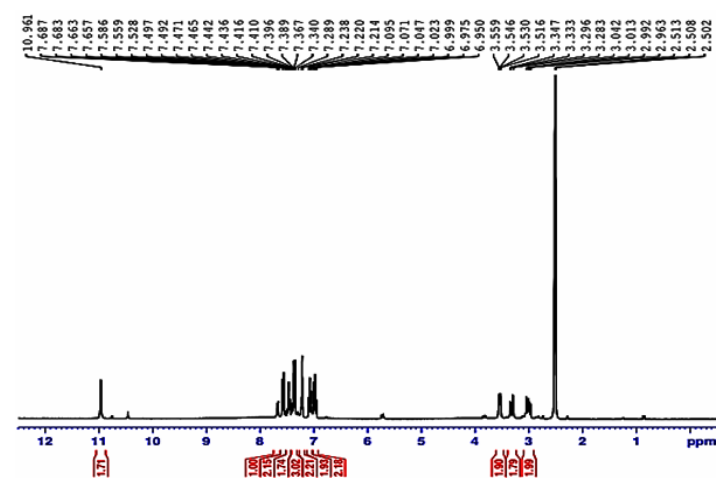

Fig. 5c. ${ }^{1} \mathrm{H}-\mathrm{NMR}$ Spectrum of TP2CIB

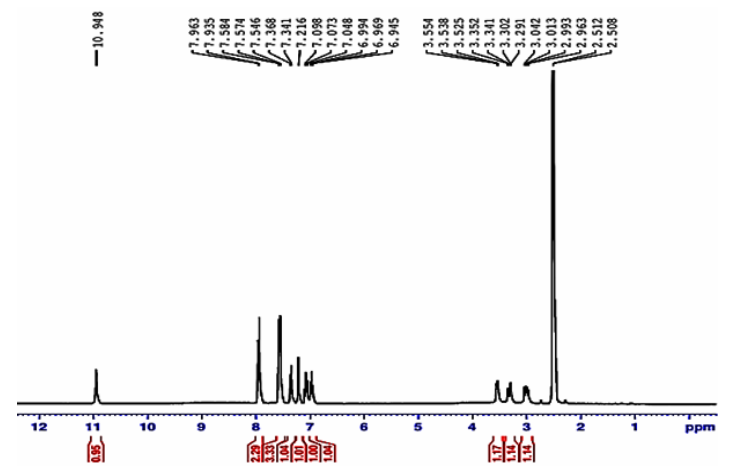

Fig. 5d. ${ }^{1} \mathrm{H}-\mathrm{NMR}$ Spectrum of TP4CIB

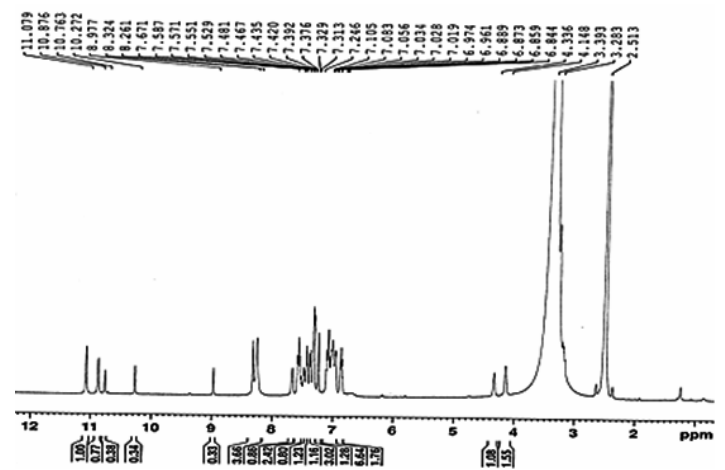

Fig. 5e. ${ }^{1} \mathrm{H}-\mathrm{NMR}$ Spectrum of Polymer Composite

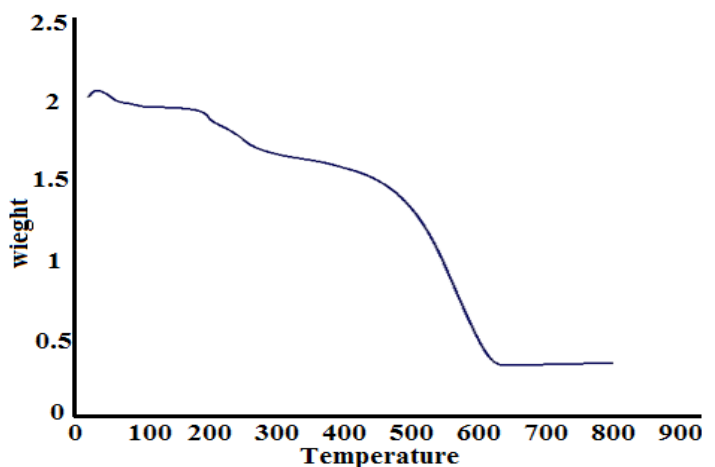

Fig. 6. Thermogravimetric analysis of polymeric Schiff base composite

\section{Antimicrobial activity}

The shortage of new antimicrobial drugs and resistance to antimicrobial agents kindled the authors to study antibacterial, antifungal and antitubercular activity using Gram-positive bacteria (Staphylococcus aureus, Bacillus subtilis and Enterococcus), Gram-negative bacteria (Proteus vulgaris, Salmonella typhi, Klebsiella pneumonia and Escherichia coli), fungai (candida albicans, Aspergillus niger, Trichoderma) and mycobacterium tuberculosis respectively. The maximum zone of inhibition for all the prepared compounds were 
determined by well method. The antimicrobial activities of all the compounds including a composite are found to increase with increase in concentration of experimental solutions (Table 2). The compound TRSA shows greater value of $Z O I$ than the control at $100 \mu \mathrm{l}$ against all the tested micro organisms while other Schiff base compound exhibit either lesser value or equal value as that of control. Thus all the chosen compounds show significant antimicrobial activity against all the strains due to the presence of azomethine moiety in all the compounds. The difference in activity may be attributed to difference in structure of molecules.

When the results at same concentrations are compared between Schiff base monomers and the composite it is revealed that the polymer is more effective than its dopant. This may be attributed to the presence of long conjugated chain present in polymeric back bone ${ }^{22}$. Polymeric antimicrobial agents have advantage over the monomers due to the fact that they are chemically stable and are not permeable through skin.

A perusal of biological study indicates that the compound TP4CIB is more effective than that of TP2CIB. This may be due to the difference in positions of $-\mathrm{Cl}$ group in both the compounds. In TP4CIB, $-\mathrm{Cl}$ is present in para position leading to more conjugation. According to the present study the polymeric composite can act as a good antibacterial and antifungal agents while the compound TRSA can be suggested as a better antitubercular agent in comparison with other prepared compounds (Figure 7).

Table 2: Antimicrobial Activity

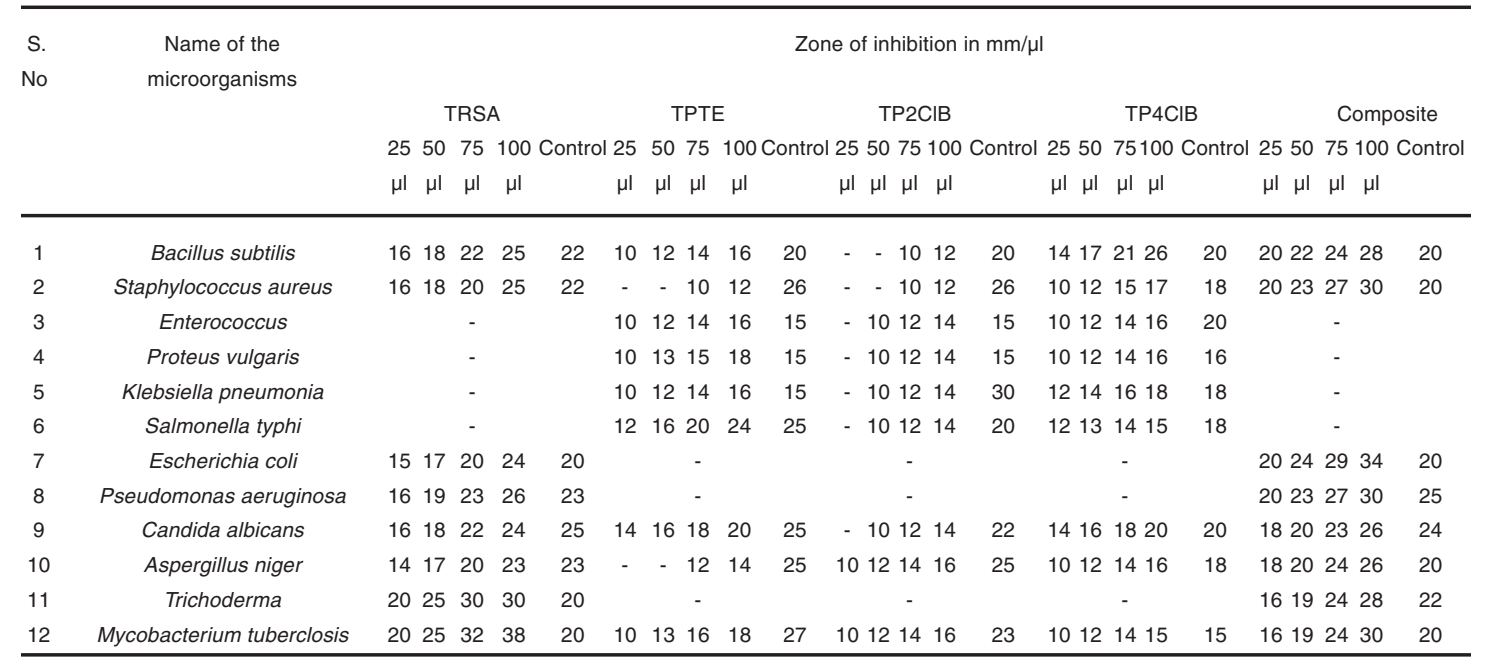

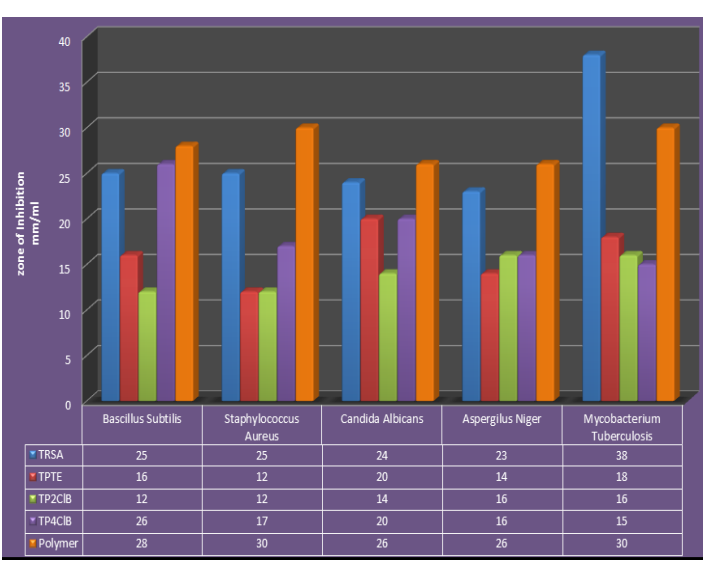

Fig. 7. Antimicrobial activity of Schiff bases and Polymer $(\mathrm{mm} / 100 \mu \mathrm{l})$
CONCLUSION

Tryptophan is an essential chemical compound that helps the body to form proteins and certain brain signaling species. The synthesis of Schiff bases from tryptophan and a polymeric composite by doping one of the imines on poly aniline chloride and characterization by spectral and analytical methods have been reported in the present paper. All the prepared imines and polymer have been evaluated for their anti microbial activity and found to have significant anti bacterial, anti fungal and anti tubercular activity against tested microorganisms. It can be concluded that all the investigated compounds may be used in various applications as anti microbial agents. 


\section{ACKNOWLEDGEMENT}

The authors acknowledge the management of Seethalakshmi Ramaswami College, Tiruchirappalli -620002 for the facilities provided to carry out the reported work. The authors express their sincere thanks to SASTRA Deemed University, Thanjavur for
NMR Study and St. Joseph College, Tiruchirappalli for UV-Visible and FT-IR studies.

\section{Conflict of Interest}

The authors declared that there is no conflict of interest regarding the publication of this paper.

\section{REFERENCES}

1. Cleiton M.da Silva; Angelo de Fatima. J. Adv. Res., 2011, 2, 1-8.

2. Tanaka, A.K.; Shimoura, R.; Caira, M. R. Tetrahedron Lett., 2010, 2, 449-452.

3. Marisol Ibarra-Rodriguez; Munoz, B.M.; Rasika Dias, H.V. J. Org. Chem., 2017, 5, 2375-2385.

4. Nabil Ramadan Bader. Rasayan J. Chem., 2010, 3, 660-670.

5. Clarke, B.; Clarke, N.; Cunningham, D.; Higgins T.; McArdle P.Ni Cholchu; O'Gara M. J. Organomet. Chem., 1998, 559, 55-64.

6. Kelode, S.R.; Mandlik, P.R.; Aswar, A.S. Orient. J. Chem., 2011, 27, 1053-1062.

7. Krishnan Suresh Kumar; Swastika Ganguly. Eur. J. Med. Chem., 2010, 45, 5474-5479.

8. Sachin R. Joshi; Seema I. Habib. Orient. J. Chem., 2014, 30, 1343-1348.

9. Mokhles M.Abd-Elzaher; Ahmed A.ElRashedy. Beni-Suef University Journal of Basic and Applied Sciences., 2016, 5, 85-96.

10. Ganesh More; Sakina Bootwala; Orient. J. Chem., 2018, 34, 800-812.

11. Scott E Harpstrite; Silvia $D$ Collins. Med. Chem., 2008, 4, 392-395.

12. Chinnasamy, R.P.; Sundararajan, R.; Govindaraj, S. J. Adv. Pharm. Technol Res., 2010, 1, 342.

13. Pandey, A.; Dewangan, D.; Verma, S.; Mishra,
A., Dubey, R.D. Int. J. Chem. Tech. Res., 2011, 3, 178-184.

14. Sathe, B.S.; Jayachandran, E.; Jagtap, V.A.; Sreenivasa, G.M. Int. J. Phar. Res., 2011, 3, 164-169.

15. Chaubey, A.K.; Pandeya, S.N. Int. J. Pharm. Technol. Res., 2012, 4, 590-598.

16. Wei, D.; Li, N.; Lu, G.; Yao, K. Sci.China B Chem. Life Sci. Earth Sci., 2006, 49, 225-229.

17. Rajeswari, B.; Santhi, R.; Radha, N. Indian J. Appl. Res., 2019, 9, 1-5.

18. Adem Cinarli; Demet Gurbuz; Aydin Javman; Seher Birteksoz A. Bull. Chem.Soc.Ethiop., 2011, 25, 407-417.

19. Silverstein, R.M., Bassler, G.C., Morril, T.C., Spectrometric Identification of organic compounds, $5^{\text {th }}$ ed., 1991, 110-111.

20. Mohamed Mustafa; Hapipah, I.; Mahmood Ameen Abdulla; Robinson Ward T. Polyhedron., 2009, 28, 3993-3998.

21. Salunke M.H.; Filmwala Z.A.; Dharap S.B.; Kamble A.D. Orient. J. Chem., 2011, 27, 1185-1191.

22. Moina Akhtar Mughal; Akhtar Hussain Mughal; Zeenat M.Ali; Ghulam Zuhra Memon; Mohammad Yar Khuhawar; Hussain sSaleem. IOSRJEN., 2013, 3, 48-55. 